British Journal of Nutrition (2021), 125, 1310-1319

doi:10.1017/S0007114520001889

(C) The Author(s), 2020. Published by Cambridge University Press on behalf of The Nutrition Society. This is an Open Access article, distributed under the terms of the Creative Commons Attribution licence (http://creativecommons.org/licenses/by/4.0/), which permits unrestricted re-use, distribution, and reproduction in any medium, provided the original work is properly cited

\title{
Increased anxiety-like behaviour is an early symptom of vitamin E deficiency that is suppressed by adrenalectomy in rats
}

\author{
Yuki Terada, Hiroya Ohashi, Yuki Otani, Kanako Tokunaga and Asako Takenaka* \\ Department of Agricultural Chemistry, School of Agriculture, Meiji University, Kawasaki, Kanagawa 214-8571, Japan \\ (Submitted 10 December 2019 - Final revision received 9 May 2020 - Accepted 26 May 2020 - First published online 1 June 2020)
}

Abstract

We previously reported that dietary vitamin $\mathrm{E}$ deficiency increased anxiety-like behaviour in rats exposed to social isolation. Here, we performed a detailed investigation of this phenomenon and its underlying mechanism. First, we fed Wistar rats with a vitamin E-free diet for $3 \mathrm{~d}$, 1 week or 2 weeks and found an increase in anxiety-like behaviour after 1 and 2 weeks of vitamin E deficiency based on behavioural indicators. Next, we examined the effect of a control diet (150 mg all-racemic $\alpha$-tocopheryl acetate/ $\mathrm{kg}$ ) on anxiety-like behaviours in rats that received a 4-week vitamin E-free diet. We found that increased anxiety-like behaviour was reversed to control levels after refeeding vitamin $\mathrm{E}$ for $7 \mathrm{~d}$ but not for 1 or $3 \mathrm{~d}$. Further, anxiety-like behaviour increased or decreased gradually based on the amount of vitamin E intake; however, it had a quicker progression than physical symptoms of vitamin E deficiency. Moreover, rats fed with excess vitamin E ( $500 \mathrm{mg}$ all-racemic $\alpha$-tocopherol/kg diet) showed less anxiety-like behaviour than control rats, indicating that vitamin E supplementation is effective for preventing anxiety increase under social isolation stress. Since plasma corticosterone levels were higher in vitamin E-deficient rats, we investigated the effect of adrenalectomy on anxiety-like behaviour and found that adrenal hormones played an essential role in the increased anxiety-like behaviour induced by vitamin $\mathrm{E}$ deficiency. In conclusion, increased anxiety-like behaviour is a symptom that emerges earlier than physical vitamin E deficiency and is caused by adrenal hormone-dependent mechanisms.

Key words: Vitamin E: Tocopherol: Anxiety-like behaviour: Adrenalectomy: Corticosterone

Vitamin $\mathrm{E}$ is a lipid-soluble vitamin with antioxidative property. It has been reported to eliminate infertility; however, the main symptom of its deficiency in humans is ataxia, which occurs in people with impaired lipid absorption or genetic disorder caused by defects in the $\alpha$-tocopherol transfer protein $(\alpha-\text { TTP })^{(1-3)}$. Furthermore, it has been reported that low dietary vitamin $\mathrm{E}$ intake increases oxidative stress ${ }^{(1)}$. Natural vitamin $\mathrm{E}$ has eight forms; namely, $\alpha, \beta, \gamma, \delta$-tocopherols and tocotrienols with $\alpha$-tocopherol being the predominant form in mammals since a specific transporter protein for $\alpha$-tocopherol, $\alpha$-TTP exists in the liver and only this vitamin $\mathrm{E}$ form is secreted into the circulation and peripheral tissues ${ }^{(4-6)}$. Most of the other vitamin $\mathrm{E}$ forms are metabolised and excreted into the urine ${ }^{(7)}$ It has been reported that $\alpha$-TTP knockout mice and patients with $\alpha$-TTP gene mutations have reduced vitamin $\mathrm{E}$ levels in the body and could demonstrate vitamin E deficiency symptoms ${ }^{(5)}$.

We previously reported an increase in anxiety-like behaviour in rats fed with a vitamin E-free diet for 4 weeks ${ }^{(8)}$. Further, the anxiogenic effect of vitamin E deficiency has been observed not only in juvenile rats but also in adult rats despite the fact that a vitamin E-free diet was less effective in lowering vitamin $\mathrm{E}$ body levels in adult rats than in juvenile rats ${ }^{(9)}$. We previously demonstrated that behavioural changes in rats fed with a vitamin E-free diet for 4 weeks were not due to ataxia since there was no impairment of motor coordination and locomotor activities ${ }^{(8)}$. Moreover, increased anxiety-like behaviour has been reported in $\alpha$-TTP knockout mice, which have low plasma and tissue vitamin E levels ${ }^{(10)}$. Increased anxiety-like behaviour has been reported in phospholipid transfer protein (PLTP) knockout mice, which have low $\alpha$-tocopherol levels in the brain but not in plasma, indicating that $\alpha$-tocopherol in the brain is involved in anxiety ${ }^{(11)}$. The increased anxiety-like behaviour in PLTP knockout mice was confirmed to be caused by vitamin E deficiency since the anxiety in 6-month-old PLTP knockout mice was prevented by vitamin E supplementation to parents ${ }^{(12)}$. Since vitamin $\mathrm{E}$ is among the most important antioxidants in the body, increased oxidative stress could be involved in the anxiety increase. Animals exposed to oxidative stress through buthionine sulfoximine treatment have been reported to show an increase in anxiety-like behaviour in a reactive oxygen

Abbreviations: $\alpha$-TTP, $\alpha$-tocopherol transfer protein; CON, control diet; EPM, elevated plus maze; PLTP, phospholipid transfer protein; TBARS, thiobarbituric acid reactive substances; -VE, vitamin E-free.

* Corresponding author: Asako Takenaka, email takenaka@meiji.ac.jp 
species-dependent manner ${ }^{(13,14)}$. Further, an association between oxidative stress and anxiety-like behaviour has been reported $^{(15)}$.

Moreover, anxiety-like behaviour has been reported to be significantly increased by vitamin $\mathrm{E}$ deficiency in rats under social isolation stress in our previous study ${ }^{(16)}$, indicating that anxiety induced by vitamin E deficiency is possibly related to the stress response mechanism. The hypothalamus-pituitaryadrenal axis is a well-known endocrine system that is strongly associated with stress and anxiety. When animals are exposed to stress, the hypothalamus secretes corticotropin-releasing factor, which triggers the pituitary to secrete adrenocorticotropic hormone ${ }^{(17)}$; consequently, adrenocorticotropic hormone induces corticosterone secretion from the adrenal cortex ${ }^{(17)}$. Corticosterone down-regulates corticotropin-releasing factor and adrenocorticotropic hormone expression and inhibits its own secretion. This negative feedback regulation prevents long-term exposure to high corticosterone levels. Many studies have reported that chronic exposure to high corticosterone levels affects nerve cells and increases anxiety behaviour ${ }^{(18-22)}$

In the present study, we first aimed to investigate the timedependent effects of vitamin E deficiency on anxiety-like behaviour in individually housed rats. Moreover, we aimed to examine the effect of vitamin $\mathrm{E}$ refeeding or excess vitamin $\mathrm{E}$ feeding in reducing anxiety. Finally, we aimed to investigate the role of adrenal hormones on increased anxiety-like behaviour due to vitamin E deficiency using adrenalectomised rats.

\section{Methods}

\section{Animal experiments}

We purchased male SPF Wistar rats (Japan Laboratory Animals Inc.) and housed them in stainless cages at $22-24^{\circ} \mathrm{C}$ under a $12 \mathrm{~h}$ light/dark cycle (06.00-18.00 hours) in a conventional animal room. The rats were fed with a commercial pellet diet (certified diet MF; Oriental Yeast) ad libitum for the first 3-5d to acclimate to the new environment. After this acclimation period, they were used for each animal experiment as described below. At the end of each experiment, the rats were dissected under anaesthesia with sodium pentobarbital ( $1 \mathrm{mg} / \mathrm{kg}$, intraperitoneal, Somnopentyl, Kyoritsu Pharmaceutical Co. Ltd). We obtained heparinised plasma and tissues and stored them at $-80^{\circ} \mathrm{C}$ until use. All the experimental procedures followed institutional and national guidelines for the care and use of animals and were approved by the Meiji University Institutional Animal Care and Use Committee (Approval Number: IACUC 15-007).

\section{Experiment with rats fed with a vitamin E-free diet for various periods}

We fed 3-week-old rats with a control (CON) or vitamin E-free (-VE) diet (Table 1) throughout the experimental period. We performed separate experiments with different durations ( $3 \mathrm{~d}, 1$ week and 2 weeks). Rats were randomly divided into the experimental groups ( $n 6$ per group) and housed with wood chip bedding. The rats were individually housed in a stainless cage $(12 \times 18 \times 11 \mathrm{~cm})$ in the 3 -d and 1 -week experiments. In the 2-week experiment, we housed three rats in a stainless cage
Table 1. Composition of the diets ( $\mathrm{g} / 100 \mathrm{~g}$ diet)

\begin{tabular}{llll}
\hline & CON & - VE & + VE \\
\hline Casein & 20 & 20 & 20 \\
$\alpha$-Maize starch & 43.67 & 43.67 & 43.67 \\
Sucrose & 21.83 & 21.83 & 21.83 \\
Cellulose & 5 & 5 & 5 \\
AIN-93 vitamin mixture & 1 & 1 & 1 \\
AIN-93 vitamin mixture (VE free) & & 3.5 & 3.5 \\
AIN-93G mineral mixture & 3.5 & 5 & 5 \\
$\begin{array}{l}\text { Maize oil } \\
\text { Stripped maize oil }\end{array}$ & 5 & & 0.05 \\
$\alpha$-Tocopherol & & & \\
\hline
\end{tabular}

VE, vitamin $\mathrm{E}$.

*AIN-93 vitamin mixture contains $1500 \mathrm{mg} / 100 \mathrm{~g}$ all-racemic $\alpha$-tocopheryl acetate.

$(15 \times 24 \times 11 \mathrm{~cm})$ for the $1 \mathrm{st}$ week and individually housed them the following week. This method allowed all the rats to be subjected to social isolation stress for 1 week before behavioural analysis. We performed the elevated plus maze (EPM) test on day 3 (3-d experiment), days 7 and 8 (1-week experiment) and day 14 (2-week experiment) and dissected the rats on days 4,9 and 17 , respectively.

\section{Experiment with rats fed with a vitamin E-free diet for 4 weeks and refed with a control diet}

We fed 3-week-old rats with a CON or -VE diet for $28 \mathrm{~d}$. Next, the rats fed with a $-\mathrm{VE}$ diet were divided into three groups and fed with a CON diet for another 1, 3 or $7 \mathrm{~d}$. Rats were randomly divided into the experimental groups ( $n 6$ per group) and housed with wood chip bedding. We housed three rats in a stainless cage $(15 \times 24 \times 11 \mathrm{~cm})$ and then individually housed them in a stainless cage $(12 \times 18 \times 11 \mathrm{~cm})$ during the last week before the EPM test. We performed the EPM test on the last day of the feeding period and dissected the rats after a 12 - $h$ fasting period on the next day after the EPM test.

\section{Experiment with rats fed with an excess vitamin $E$ diet or vitamin E-free diet}

We fed 3-week-old rats with a CON, -VE or +VE diet (added $500 \mathrm{mg} / \mathrm{kg}$ all-racemic $\alpha$-tocopherol to the $-\mathrm{VE}$ diet) (Table 1) for 4 weeks. Rats were randomly divided into the experimental groups ( $n 6$ per group) and housed with wood chip bedding. We housed three rats in a stainless cage $(15 \times 24 \times 11 \mathrm{~cm})$ for 3 weeks and then individually housed them in a stainless cage $(12 \times 18 \times 11 \mathrm{~cm})$ during the last week before the EPM test. The EPM test was performed on day 30 , and the rats were dissected on day 34 .

\section{Experiment with adrenalectomised rats fed with a vitamin E-free diet}

We adrenalectomised or sham-operated 5-week-old rats and fed them with a CON or -VE diet for 4 weeks. Rats were randomly divided into the experimental groups ( $n 6$ per group) and housed with wood chip bedding. All the rats had free access to a $0.88 \% \mathrm{NaCl}$ solution after surgery. We housed three rats in a stainless cage $(15 \times 24 \times 11 \mathrm{~cm})$ and then individually housed them in a stainless cage $(12 \times 18 \times 11 \mathrm{~cm})$ during the last week before the EPM test. The EPM test was performed 
on day 28 , and the rats were dissected after a 12 -h fasting period on day 29.

\section{Elevated plus maze test}

The EPM test was performed as previously described ${ }^{(23)}$ with an apparatus composed of two open arms $(50 \times 10 \mathrm{~cm})$ and two closed arms $(50 \times 10 \times 40 \mathrm{~cm})$ elevated $50 \mathrm{~cm}$ from the floor. We video-recorded the rats' behaviour for $15 \mathrm{~min}$ and analysed the activity on the open arms, head dipping, stretch-out posture and locomotion. We used the first three indicators to evaluate anxiety behaviour and used locomotion to evaluate spontaneous motor activity.

\section{$\alpha$-Tocopherol}

We measured tissue or plasma $\alpha$-tocopherol levels using highperformance liquid chromatography as previously described ${ }^{(9)}$.

\section{Thiobarbituric acid reactive substances}

We measured tissue or plasma thiobarbituric acid reactive substances (TBARS) levels using the fluorescence method as previously described ${ }^{(9)}$.

\section{Plasma corticosterone}

We used heparinised plasma samples that were collected right after the EPM tests. We measured the corticosterone levels using an AssayMax Corticosterone ELISA Kit (Assaypro).

\section{Statistical analysis}

We used Student's $t$ test or Welch's $t$ test to perform betweengroup comparisons of values depending on whether they had equal or unequal homogeneity of variances, respectively. We performed the Mann-Whitney $U$ test for non-normal data sets. We used one-way ANOVA and post hoc tests (Tukey-Kramer) to analyse differences among the three experimental groups that received excess vitamin $\mathrm{E}$. We used two-way ANOVA to evaluate the effects of two factors simultaneously in the adrenalectomy experiment. We compared the corresponding CON and -VE groups when we observed a significant interaction be the two evaluated factors. All statistical analyses were performed using Statistics 2008 (Social Survey Research Information Co. Ltd) for Excel and the differences were considered significant at $P<0 \cdot 05$.

\section{Results \\ Experiment with rats fed with a vitamin E-free diet for various periods}

The body weight was not affected by vitamin E deficiency, while there was a significant decrease in plasma, liver and cortex $\alpha$-tocopherol levels in all the examined durations (Table 2). Vitamin E deficiency induced an increase in plasma and liver levels of TBARS after 1 or 2 weeks of vitamin E deficiency compared with those in the control groups; however, there was no significant increase in the cortex levels. Vitamin E deficiency for $3 \mathrm{~d}$ resulted in an increase in TBARS level in plasma, but not in either the liver or the cortex (Table 2). We have demonstrated that 1 week and 2 weeks of vitamin $\mathrm{E}$ deficiency induces an increase in plasma corticosterone levels compared with those in the control groups (Table 2). In the EPM test, there was a decrease in open arm activity after 2 weeks of vitamin E deficiency while a change in head dipping and stretch out was observed after 1 week (Fig. 1). There was no effect of vitamin E deficiency on locomotion in all the examined durations (Fig. 1). The EPM test results demonstrated an increase in anxiety-like behaviour after 1 or 2 weeks of vitamin $\mathrm{E}$ deficiency depending on the behavioural indicators.

\section{Experiment with rats refed with vitamin $E$ after receiving a vitamin E-free diet for 4 weeks}

The body weight and food intake were not affected by vitamin $\mathrm{E}$ deficiency or refeeding except for a slight increase in food intake in rats refed with vitamin $\mathrm{E}$ for $3 \mathrm{~d}$ (Table 3). Feeding a

Table 2. Characteristics of the rats fed vitamin E-free (-VE) diet for various periods (Mean values with their standard errors)

\begin{tabular}{|c|c|c|c|c|c|c|c|c|c|c|c|c|}
\hline & \multicolumn{4}{|c|}{$3 d$} & \multicolumn{4}{|c|}{1 week } & \multicolumn{4}{|c|}{2 weeks } \\
\hline & \multirow{2}{*}{\multicolumn{2}{|c|}{$\frac{\mathrm{CON}}{n 12}$}} & \multirow{2}{*}{\multicolumn{2}{|c|}{$\frac{-\mathrm{VE}}{n 12}$}} & \multirow{2}{*}{\multicolumn{2}{|c|}{$\frac{\text { CON }}{n 12}$}} & \multirow{2}{*}{\multicolumn{2}{|c|}{$\frac{-\mathrm{VE}}{n 12}$}} & \multirow{2}{*}{\multicolumn{2}{|c|}{$\frac{\mathrm{CON}}{n 6}$}} & \multirow{2}{*}{\multicolumn{2}{|c|}{$\frac{-\mathrm{VE}}{n 6}$}} \\
\hline & & & & & & & & & & & & \\
\hline & Mean & SEM & Mean & SEM & Mean & SEM & Mean & SEM & Mean & SEM & Mean & SEM \\
\hline Body weight change (g/d) & 5.99 & 0.17 & $5 \cdot 70$ & 0.22 & $5 \cdot 27$ & 0.11 & $5 \cdot 26$ & 0.11 & 8.01 & 0.32 & $8 \cdot 24$ & 0.22 \\
\hline $\begin{array}{l}\text { Food intake }(\mathrm{g} / \mathrm{d}) \dagger \\
\alpha \text {-Tocopherol }\end{array}$ & $12 \cdot 10$ & 0.38 & $12 \cdot 56$ & 0.33 & 12.97 & 0.44 & $13 \cdot 15$ & 0.17 & $19 \cdot 76$ & 0.64 & $20 \cdot 11$ & 0.39 \\
\hline Plasma $(\mu \mathrm{g} / \mathrm{ml})$ & $15 \cdot 42$ & 0.67 & $5 \cdot 44^{\star \star}$ & 0.19 & $20 \cdot 32$ & 1.54 & $5 \cdot 06^{\star *}$ & 0.76 & $17 \cdot 02$ & $1 \cdot 20$ & $1 \cdot 74^{\star \star}$ & 0.07 \\
\hline Liver $(\mu \mathrm{g} / \mathrm{g})$ & $40 \cdot 55$ & 1.36 & $10 \cdot 78^{\star \star}$ & 0.45 & $61 \cdot 83$ & 1.39 & $15 \cdot 99^{\star \star}$ & $2 \cdot 51$ & $52 \cdot 74$ & $8 \cdot 98$ & $6 \cdot 82^{\star \star}$ & 1.33 \\
\hline Cortex $(\mu \mathrm{g} / \mathrm{g})$ & $12 \cdot 71$ & 0.64 & $9 \cdot 76^{\star *}$ & 0.41 & $17 \cdot 54$ & 1.39 & $11 \cdot 33^{\star \star}$ & 0.44 & $29 \cdot 49$ & $2 \cdot 11$ & $14 \cdot 76^{\star \star}$ & $2 \cdot 80$ \\
\hline TBARS & & & & & & & & & & & & \\
\hline Plasma (TEP eq. $\mathrm{nmol} / \mathrm{ml}$ ) & 0.20 & 0.01 & $0 \cdot 29^{\star *}$ & 0.01 & 0.22 & 0.01 & $0 \cdot 31^{\star \star}$ & 0.02 & 0.17 & 0.02 & $0.24^{*}$ & 0.02 \\
\hline Liver (TEP eq. $\mathrm{nmol} / \mathrm{g}$ ) & 44.47 & $3 \cdot 24$ & 41.43 & 8.44 & $38 \cdot 24$ & $4 \cdot 13$ & $99 \cdot 60^{* * *}$ & 12.45 & $16 \cdot 38$ & 2.46 & $35 \cdot 61^{*}$ & 6.35 \\
\hline Cortex (TEP eq. $\mathrm{nmol} / \mathrm{g}$ ) & $33 \cdot 81$ & 3.85 & 34.97 & $6 \cdot 32$ & $27 \cdot 98$ & 4.96 & $20 \cdot 20$ & 4.46 & $12 \cdot 38$ & $1 \cdot 24$ & $24.39^{P=0.040}$ & 4.94 \\
\hline Plasma corticosterone (ng/ml) & $124 \cdot 4$ & 21.5 & $67 \cdot 3^{*}$ & 9.6 & 178.4 & $4 \cdot 1$ & $199 \cdot 8^{*}$ & $7 \cdot 1$ & $217 \cdot 0$ & 11.9 & 239.6 & $7 \cdot 4$ \\
\hline
\end{tabular}

CON, control diet; TBARS, thiobarbituric acid reactive substances; TEP eq., tetraethoxypropane equivalent.

$P$ value $P<0.1 ;{ }^{*} P<0.05,{ }^{\star *} P<0.01$.

† Food intake; daily food intake during the last 1 week of the individual housing (2 weeks groups). 
(a)

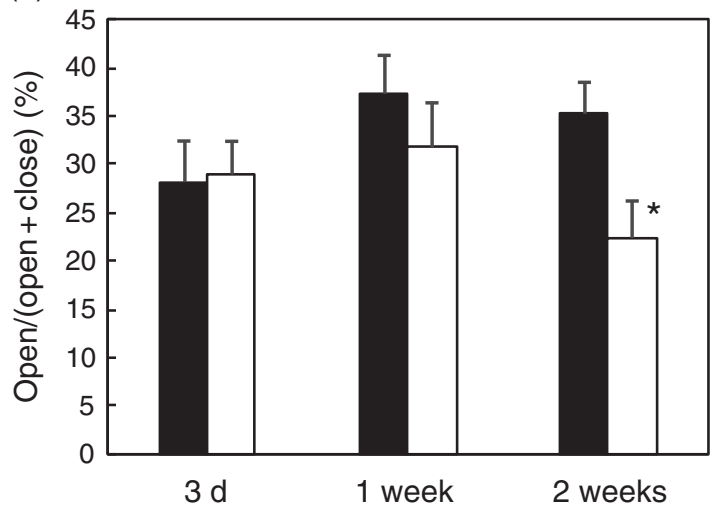

(c)

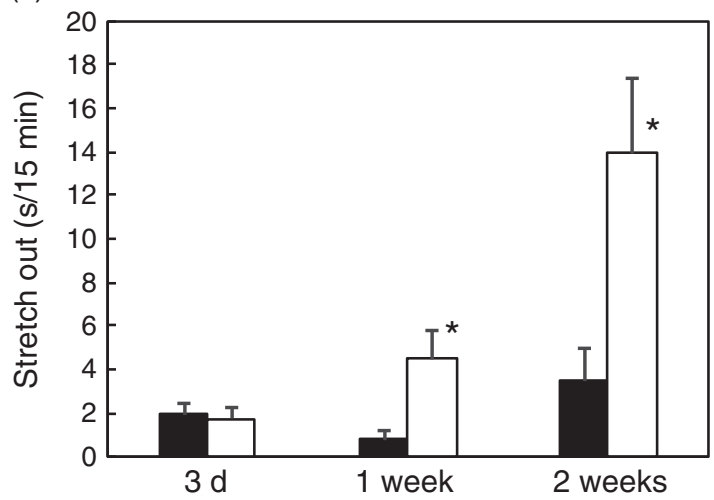

(b)

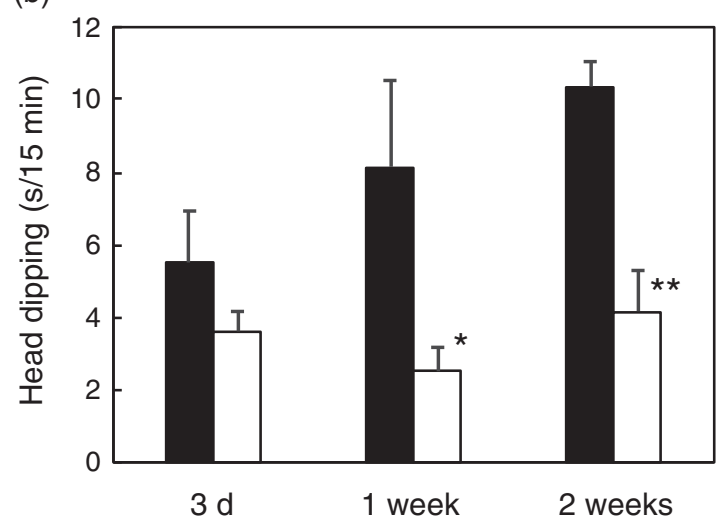

(d)

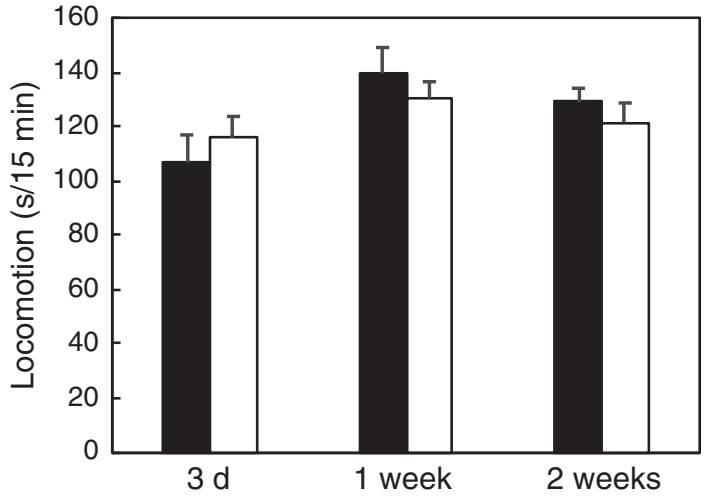

Fig. 1. Effect of vitamin $E$ deficiency for various periods on anxiety-like behaviour in rats. The rats were fed with a control (CON) or vitamin E-free (-VE) diet for $3 \mathrm{~d}$, 1 week or 2 weeks. We analysed open arm activity (a), head dipping (b), stretch out (c) and locomotion (d) in the 15-min elevated plus-maze (EPM) test. Values are means with their standard errors ( $n 6$ per group). Mean value is significantly different from that of the CON group: ${ }^{*} P<0.05,{ }^{* *} P<0.01$. $\square$, CON; $\square,-$ VE.

Table 3. Characteristics of the rats refed vitamin $E$ after feeding vitamin E-free (-VE) diet for 4 weeks (Mean values with their standard errors)

\begin{tabular}{|c|c|c|c|c|c|c|c|c|c|c|}
\hline & & & & & \multicolumn{6}{|c|}{ Refed CON } \\
\hline & \multicolumn{2}{|c|}{ CON } & \multicolumn{2}{|c|}{$-\mathrm{VE}$} & \multicolumn{2}{|l|}{$1 d$} & \multicolumn{2}{|l|}{$3 d$} & \multicolumn{2}{|c|}{$7 d$} \\
\hline & \multicolumn{2}{|c|}{$n 6$} & \multicolumn{2}{|c|}{$n 6$} & \multicolumn{2}{|l|}{$n 6$} & \multicolumn{2}{|l|}{$n 6$} & \multicolumn{2}{|c|}{$n 6$} \\
\hline & Mean & SEM & Mean & SEM & Mean & SEM & Mean & SEM & Mean & SEM \\
\hline Body weight change (g/d) & $7 \cdot 47$ & 0.20 & $7 \cdot 47$ & 0.17 & $7 \cdot 47$ & $0 \cdot 19$ & $7 \cdot 69$ & 0.08 & 6.92 & 0.26 \\
\hline $\begin{array}{l}\text { Food intake }(\mathrm{g} / \mathrm{d}) \ddagger \\
\alpha \text {-Tocopherol }\end{array}$ & $24 \cdot 6$ & 0.4 & $23 \cdot 0$ & 0.7 & $24 \cdot 2$ & $1 \cdot 1$ & $25 \cdot 3^{*}$ & 0.5 & $23 \cdot 8$ & 0.7 \\
\hline Plasma $(\mu \mathrm{g} / \mathrm{ml})$ & 11.60 & 0.62 & $3.24 \dagger \dagger$ & 0.08 & $6 \cdot 26^{\star \star}$ & 0.43 & $8 \cdot 84^{\star *}$ & 0.14 & $11.91^{\star *}$ & 0.42 \\
\hline Liver $(\mu \mathrm{g} / \mathrm{g})$ & 38.99 & $5 \cdot 86$ & $6.43 \dagger \dagger$ & 0.98 & $14 \cdot 87^{\star \star}$ & 1.93 & $29 \cdot 78^{\star \star}$ & 0.96 & $38 \cdot 49^{\star}$ & $9 \cdot 39$ \\
\hline Cortex $(\mu \mathrm{g} / \mathrm{g})$ & $15 \cdot 63$ & $2 \cdot 71$ & $7.79 \dagger$ & 0.55 & $10 \cdot 35^{\star}$ & 0.76 & $7 \cdot 48$ & 0.85 & $14 \cdot 74^{\star \star}$ & $1 \cdot 33$ \\
\hline TBARS & & & & & & & & & & \\
\hline Plasma (TEP eq./ml) & $0 \cdot 12$ & 0.04 & $0.41 \dagger \dagger$ & 0.07 & $0.27^{P=0.091}$ & 0.02 & $0.24^{P=0.065}$ & 0.04 & $0.20^{\star}$ & 0.05 \\
\hline Liver (TEP eq./g) & 42.5 & 3.5 & $77 \cdot 1 \dagger \dagger$ & $5 \cdot 8$ & $56 \cdot 6^{*}$ & 4.9 & $53 \cdot 8^{*}$ & 4.9 & $50 \cdot 0^{\star \star}$ & 3.4 \\
\hline Cortex (TEP eq./g) & $43 \cdot 1$ & $5 \cdot 7$ & 84.8†† & $4 \cdot 0$ & $90 \cdot 1$ & $7 \cdot 9$ & $71 \cdot 8$ & $13 \cdot 5$ & $81 \cdot 7$ & $15 \cdot 7$ \\
\hline Plasma corticosterone (ng/ml) & $146 \cdot 3$ & $41 \cdot 6$ & $324 \cdot 1^{P=0} 0.051$ & $68 \cdot 8$ & $208 \cdot 6$ & $54 \cdot 7$ & 229.5 & $54 \cdot 8$ & $169 \cdot 5^{P=0.081}$ & $40 \cdot 4$ \\
\hline
\end{tabular}

CON, control diet; TBARS, thiobarbituric acid reactive substances; TEP eq., tetraethoxypropane equivalent.

$P$ value $P<0.1,{ }^{*} P<0.05,{ }^{\star *} P<0.01,-$ VE v. $1,3,7 \mathrm{~d}$

$P$ value $P<0.1$, $P<0.05$, t† $P<0.01$, CON $v$. $-\mathrm{VE}$.

$\ddagger$ Food intake, daily food intake during the last 1 week of the individual housing.

vitamin E-free diet decreased the plasma, liver and cortex $\alpha$-tocopherol levels, which were recovered by vitamin $\mathrm{E}$ refeeding (Table 3). Vitamin E deficiency increased the plasma, liver and cortex TBARS levels with the plasma and liver levels being reduced by vitamin E refeeding (Table 3). Vitamin E deficiency tended to increase plasma corticosterone levels, which on subsequent vitamin $\mathrm{E}$ refeeding, tended to reduce (Table 3). Vitamin E deficiency increased anxiety-like behaviour in open 

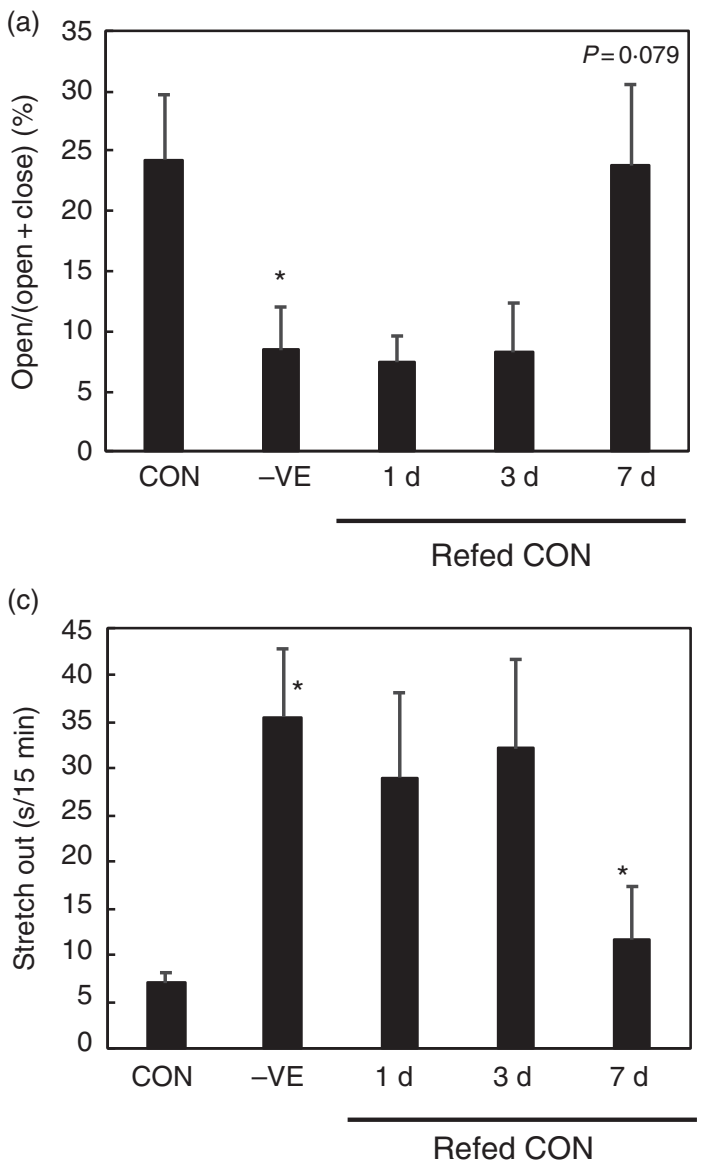

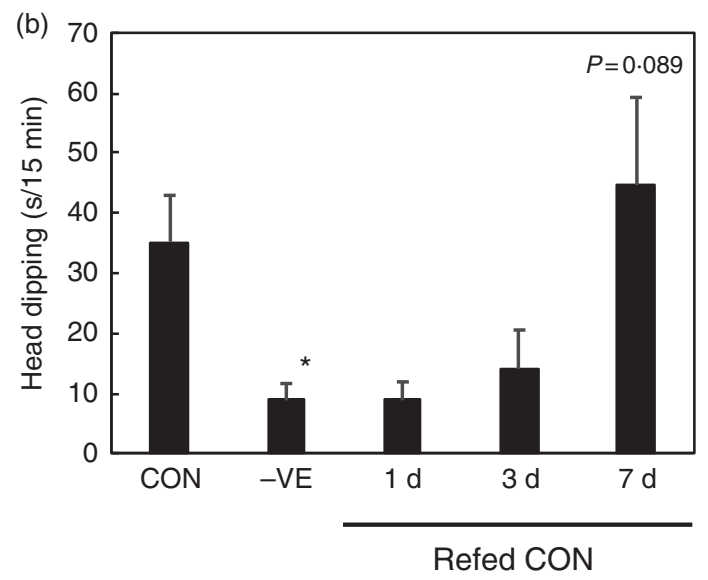

(d)

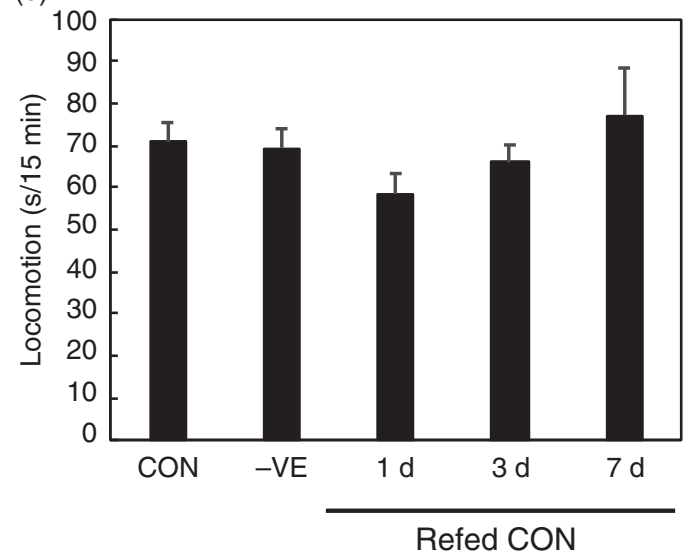

Fig. 2. Effect of vitamin E refeeding on anxiety-like behaviour in vitamin E-deficient rats. The rats were fed with a control (CON) or vitamin E-free diet (-VE) diet for $28 \mathrm{~d}$. Next, the rats fed with a -VE diet were divided into three groups and then refed with a CON diet for another 1, 3 or $7 \mathrm{~d}$. We analysed open arm activity (a), head dipping (b), stretch out (c) and locomotion (d) in the 15-min elevated plus-maze (EPM) test. Values are means with their standard errors ( $n 6$ per group). Differences between CON and -VE are shown as * $P<0.05$ on - VE bar chart. Differences between - VE and 1,3 or $7 \mathrm{~d}$ are shown as $P$ value when $P<0.1$ or ${ }^{*} P<0.05$ on 1,3 or $7 \mathrm{~d}$ bar chart.

arm activity, head dipping and stretch out (Fig. 2). Vitamin E refeeding significantly decreased anxiety-like behaviour in stretch out and tended to decrease them in open arm activity and head dipping (Fig. 2). Vitamin E deficiency or refeeding did not affect locomotion (Fig. 2).

\section{Experiment with rats fed with a vitamin E-free or excess vitamin E diet}

The body weight and food intake were not affected by feeding with a vitamin E-free or excess vitamin E diet (Table 4). Vitamin E deficiency and excess vitamin E feeding decreased and increased plasma and liver $\alpha$-tocopherol levels, respectively (Table 4). The amount of dietary vitamin E did not significantly affect cortex $\alpha$-tocopherol levels (Table 4). Plasma and liver TBARS levels were increased by vitamin E deficiency but were not affected by excess vitamin $\mathrm{E}$ intake (Table 4). The amount of dietary vitamin $\mathrm{E}$ did not significantly affect cortex TBARS levels (Table 4). Plasma corticosterone levels were increased by vitamin $\mathrm{E}$ deficiency but were not affected by excess vitamin E intake (Table 4). Anxiety-like behaviour in the open arm and stretch out activities tended to increase with vitamin E deficiency and subsequently tended to reduce with excess vitamin $\mathrm{E}$ intake
(Fig. 3). The amount of dietary vitamin E did not affect head dipping and locomotion (Fig. 3).

\section{Experiment with adrenalectomised rats fed with vitamin E-free diets}

Vitamin E deficiency increased food intake but did not affect body weight in either the sham-operated or adrenalectomised rats (Table 5). Vitamin E deficiency decreased plasma, liver and cortex $\alpha$-tocopherol levels (Table 5). Plasma and liver TBARS levels were affected by vitamin E deficiency, while the cortex levels were affected by adrenalectomy (Table 5). Adrenalectomy decreased plasma corticosterone levels (Table 5). Anxiety-like behaviour was increased by vitamin E deficiency in the sham-operated rats but was not increased in the adrenalectomised rats in open arm activity, head dipping and stretch out (Fig. 4). Locomotion was slightly increased by adrenalectomy (Fig. 4).

\section{Discussion}

Our findings demonstrate the time-dependent changes of $\alpha$-tocopherol levels, oxidative stress marker levels and anxiety-like behaviour in rats fed with a vitamin E-free diet. 
Table 4. Characteristics of the rats fed vitamin E-free (-VE) diet or diet with excess vitamin E (+VE) (Mean values with their standard errors)

\begin{tabular}{|c|c|c|c|c|c|c|}
\hline & \multicolumn{2}{|c|}{$-\mathrm{VE}$} & \multicolumn{2}{|c|}{ CON } & \multicolumn{2}{|c|}{$+\mathrm{VE}$} \\
\hline & \multicolumn{2}{|c|}{$n 6$} & \multicolumn{2}{|c|}{$n 6$} & \multicolumn{2}{|c|}{$n 6$} \\
\hline & Mean & SEM & Mean & SEM & Mean & SEM \\
\hline Body weight change (g/d) & $7 \cdot 28$ & 0.25 & $7 \cdot 14$ & 0.30 & 6.45 & 0.30 \\
\hline $\begin{array}{l}\text { Food intake }(\mathrm{g} / \mathrm{d})^{*} \\
\alpha \text {-Tocopherol }\end{array}$ & $22 \cdot 8$ & 0.5 & $22 \cdot 3$ & 0.3 & $22 \cdot 3$ & 0.8 \\
\hline Plasma $(\mu \mathrm{g} / \mathrm{ml})$ & $0.56^{a}$ & 0.06 & $7 \cdot 87^{b}$ & 0.88 & $12 \cdot 34^{c}$ & 1.40 \\
\hline Cortex $(\mu \mathrm{g} / \mathrm{g})$ & 4.42 & 0.61 & $12 \cdot 78$ & $2 \cdot 26$ & $14 \cdot 11$ & $4 \cdot 20$ \\
\hline TBARS & & & & & & \\
\hline Plasma (TEP eq./ml) & $0.48^{a}$ & 0.03 & $0.27^{b}$ & 0.02 & $0 \cdot 19^{b}$ & 0.02 \\
\hline Liver (TEP eq./g) & $54.65^{\mathrm{a}}$ & $6 \cdot 73$ & $25 \cdot 61^{b}$ & $4 \cdot 32$ & $25 \cdot 35^{b}$ & 2.03 \\
\hline Cortex (TEP eq./g) & $27 \cdot 72$ & $2 \cdot 38$ & $26 \cdot 77$ & 3.43 & $20 \cdot 19$ & 2.96 \\
\hline Plasma corticosterone $(\mathrm{ng} / \mathrm{ml})$ & $420 \cdot 2^{a}$ & 54.9 & $187 \cdot 1^{\mathrm{b}}$ & $43 \cdot 3$ & $115 \cdot 9^{b}$ & $20 \cdot 2$ \\
\hline
\end{tabular}

CON, control diet; TBARS, thiobarbituric acid reactive substances; TEP eq., tetraethoxypropane equivalent.

a,b,c Mean values in a row with unlike superscript letters are significantly different $(P<0.05)$.

* Food intake, daily food intake during the last 1 week of the individual housing.

(a)

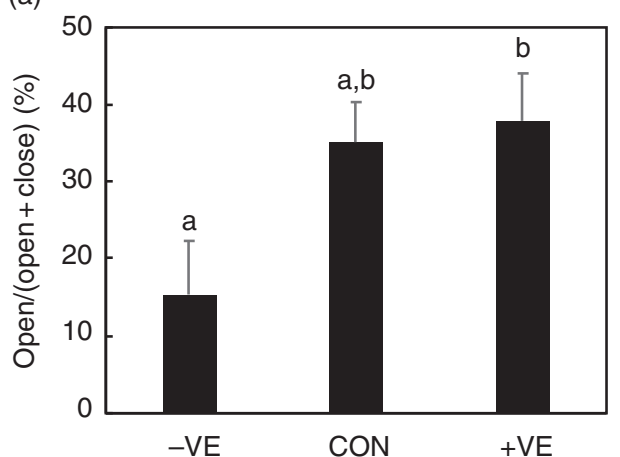

(c)

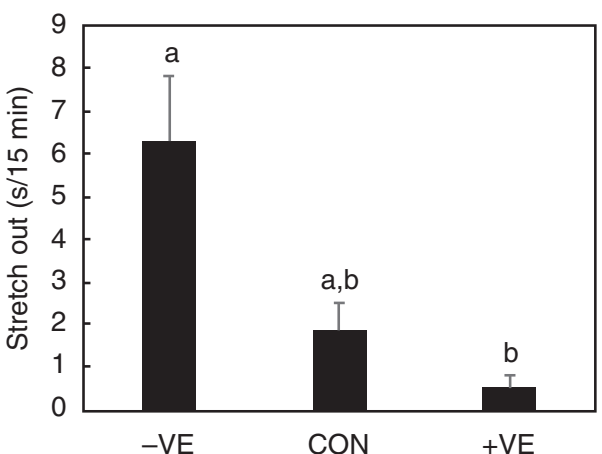

(b)

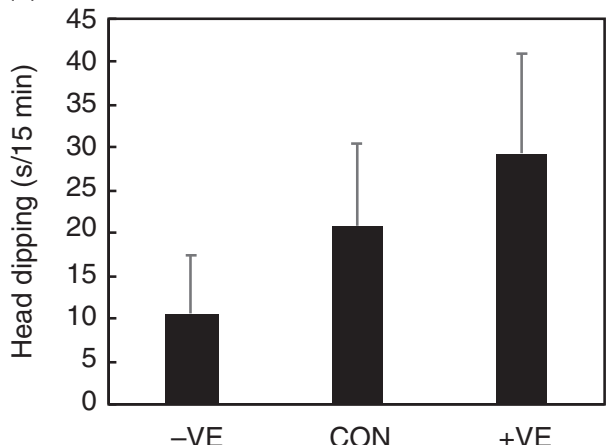

(d)

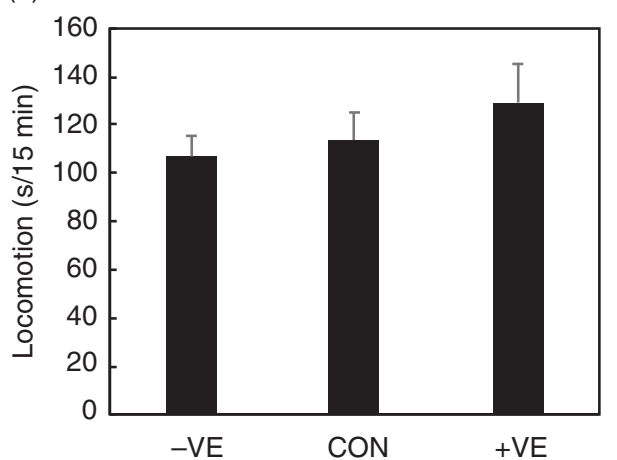

Fig. 3. Effect of vitamin deficiency or excess vitamin $\mathrm{E}$ feeding on anxiety-like behaviour in rats. The rats were fed with a control (CON) diet, vitamin E-free (-VE) diet or a diet with $500 \mathrm{mg} / \mathrm{kg}$ vitamin $\mathrm{E}$ (+VE) for 4 weeks. We analysed open arm activity (a), head dipping (b), stretch out (c) and locomotion (d) in the 15-min elevated plus-maze (EPM) test. Values are means with their standard errors ( $n 6$ per group). ${ }^{a, b}$ Mean values with unlike letters are significantly different according to post hoc analysis $(P<0.05)$.

Regarding the oxidative stress marker, there was a slower increase in TBARS levels than decrease in $\alpha$-tocopherol levels in all the examined tissues. Further, there was a faster increase in anxiety-like behaviour than that of TBARS levels, which could be attributed to the fact that TBARS is generated through a multistep reaction. Although there was decline in plasma, liver and cortex $\alpha$-tocopherol levels after $3 \mathrm{~d}$ of receiving a vitamin E-free diet, rate of decrease in the cortex was small. This is consistent with the previously reported slower vitamin $\mathrm{E}$ decline in the brain than in other tissues in vitamin E-deprived mice ${ }^{(24,25)}$. Regarding brain vitamin E levels, which we hypothesise to be associated with increased anxiety behaviour, the cortex $\alpha$-tocopherol levels decreased to $75 \%$ of those observed in control rats after 1 week of receiving vitamin E-free diet when the anxiety increase began. These findings, together with the previous findings that brain $\alpha$-tocopherol levels in PLTP 
Table 5. Characteristics of the rats with or without adrenalctomy and fed control (CON) or vitamin E-free (-VE) diet (Mean values with their standard errors)

\begin{tabular}{|c|c|c|c|c|c|c|c|c|c|c|c|}
\hline & \multicolumn{4}{|c|}{ SHAM } & \multicolumn{4}{|c|}{ ADEX } & & & \\
\hline & \multirow{2}{*}{\multicolumn{2}{|c|}{$\frac{\mathrm{CON}}{n 6}$}} & \multirow{2}{*}{\multicolumn{2}{|c|}{$\frac{-V E}{n 6}$}} & \multirow{2}{*}{\multicolumn{2}{|c|}{$\frac{\mathrm{CON}}{n 6}$}} & \multirow{2}{*}{\multicolumn{2}{|c|}{$\frac{-V E}{n 6}$}} & \multicolumn{3}{|c|}{ Two-way ANOVA } \\
\hline & & & & & & & & & \multirow[b]{2}{*}{$-V E$} & \multirow[b]{2}{*}{ ADEX } & \multirow[b]{2}{*}{$-\mathrm{VE} \times \mathrm{ADEX}$} \\
\hline & Mean & SEM & Mean & SEM & Mean & SEM & Mean & SEM & & & \\
\hline Body weight change $(\mathrm{g} / \mathrm{d}) \dagger$ & 6.43 & 0.28 & $6 \cdot 70$ & 0.30 & $6 \cdot 13$ & 0.54 & $6 \cdot 68$ & $0 \cdot 27$ & NS & NS & NS \\
\hline $\begin{array}{l}\text { Food intake }(\mathrm{g} / \mathrm{d}) \ddagger \\
\alpha \text {-Tocopherol }\end{array}$ & $24 \cdot 4$ & $1 \cdot 3$ & $29 \cdot 3$ & $0 \cdot 2$ & $25 \cdot 7$ & 1.4 & $27 \cdot 0$ & 0.7 & * & NS & NS \\
\hline Plasma $(\mu \mathrm{g} / \mathrm{ml})$ & $14 \cdot 81$ & 0.57 & $4 \cdot 41$ & 0.28 & 14.93 & $1 \cdot 13$ & 3.96 & 0.09 & ** & NS & NS \\
\hline Liver $(\mu \mathrm{g} / \mathrm{g})$ & 35.98 & 3.41 & 1.65 & 0.09 & 33.92 & $5 \cdot 07$ & $1 \cdot 22$ & 0.08 & $\star \star$ & NS & NS \\
\hline Cortex $(\mu \mathrm{g} / \mathrm{g})$ & 23.25 & 1.52 & 11.03 & $1 \cdot 32$ & 19.92 & 3.00 & $10 \cdot 72$ & 1.09 & ** & NS & NS \\
\hline \multicolumn{12}{|l|}{ TBARS } \\
\hline Plasma (TEP eq./ml) & 0.756 & 0.028 & 0.979 & 0.039 & 0.737 & 0.052 & 0.905 & 0.081 & ** & NS & NS \\
\hline Liver (TEP eq./g) & 34.65 & $6 \cdot 63$ & $74 \cdot 27$ & $13 \cdot 90$ & $45 \cdot 28$ & 4.09 & $72 \cdot 71$ & 6.93 & ** & NS & NS \\
\hline Cortex (TEP eq./g) & $56 \cdot 49$ & 9.42 & $76 \cdot 15$ & 4.18 & 81.00 & 5.45 & $80 \cdot 85$ & 4.91 & NS & * & NS \\
\hline Plasma corticosterone (ng/ml) & $172 \cdot 4$ & $39 \cdot 3$ & $267 \cdot 6$ & $65 \cdot 2$ & $76 \cdot 46$ & $20 \cdot 66$ & $122 \cdot 84$ & 41.60 & NS & * & NS \\
\hline
\end{tabular}

SHAM, sham-operated; ADEX, adrenalectomised; TBARS, thiobarbituric acid reactive substances; TEP eq., tetraethoxypropane equivalent.

${ }^{\star} P<0.05,{ }^{* *} P<0.01$.

$\dagger$ Body weight gain during feeding experimental diet.

(a)

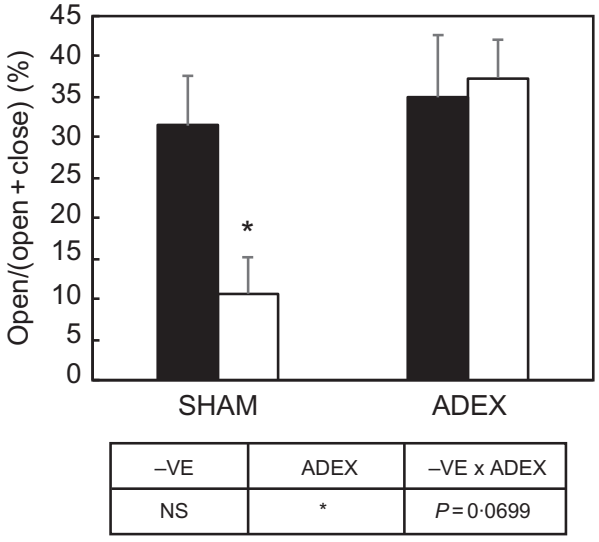

(c)

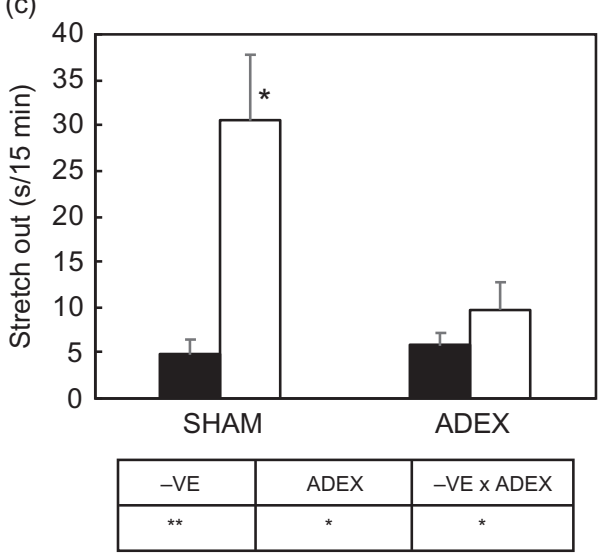

(b)

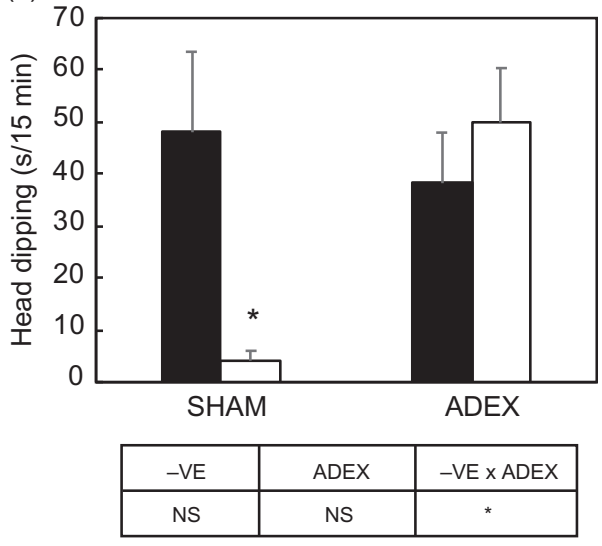

(d)

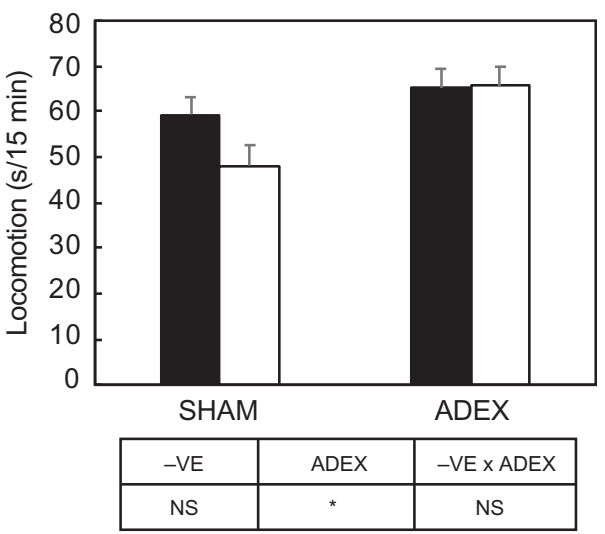

Fig. 4. Effect of adrenalectomy on anxiety-like behaviour in rats due to vitamin $E$ deficiency. The rats were sham-operated (SHAM) or adrenalectomised (ADEX) and were fed with a control (CON) or vitamin E-free (-VE) diet for 4 weeks. We analysed open arm activity (a), head dipping (b), stretch out (c) and locomotion (d) in the 15-min elevated plus-maze (EPM) test. Values are means with their standard errors ( $n 6$ per group). Two-way ANOVA results are shown below each graph (NS, ${ }^{*} P<0.05, P$ value when $P<0.1$. Differences between the two dietary groups in the same surgery group were analysed when effect of interaction was observed in two-way ANOVA. $\square$, CON; $\square,-V E$. 
knockout mice were reduced to $70 \%$ of those in wild-type mice ${ }^{(11)}$, indicate that a decrease in the level of brain $\alpha$-tocopherol would increase the risk of increased anxiety-like behaviour.

In the EPM test, a 2-week vitamin E-deficient diet significantly increased anxiety-like behaviour in open arm activity, while a 1-week vitamin E-deficient diet increased anxiety-like behaviour in stretch out and head dipping. Similarly, we previously reported that stretch out and head dipping were more sensitive indicators of anxiety in vitamin E-deficient rats ${ }^{(16)}$. These findings indicate that the effect of vitamin $\mathrm{E}$ deficiency on anxiety-like behaviour is not acute but rather progresses over time. Moreover, 1 week of vitamin $\mathrm{E}$ refeeding restored the increased anxiety to normal levels. These results suggest that the increase or decrease in anxiety-like behaviour is caused by a mechanism that gradually changes with an increase or decrease in vitamin $\mathrm{E}$.

However, increased anxiety-like behaviour has been reported to occur much earlier than the physical symptoms of vitamin $\mathrm{E}$ deficiency, which were reported to occur after 12 weeks in rats fed with a vitamin E-deficient diet ${ }^{(26)}$. This indicates that anxiety-like behaviour is a more sensitive indicator of vitamin $\mathrm{E}$ deficiency than physical symptoms. Moreover, we found that rats fed with excess vitamin $\mathrm{E}$ had less anxiety-like behaviour and lower TBARS levels than control rats under social isolation. These results suggest that vitamin E supplementation to the control diet might be effective to prevent stress-related anxiety even when the control diet contains enough vitamin $\mathrm{E}$ amounts to maintain physical health. Lower vitamin E levels have been reported in patients with major depression ${ }^{(12)}$, as well as a beneficial effect of vitamin $\mathrm{E}$ intake on Alzheimer's disease $^{(27)}$; however, these previous findings remain controversial.

Since plasma corticosterone levels right after the EPM test were higher in the vitamin E-deficient rats than in the control rats, we investigated the involvement of corticosterone in increased anxiety-like behaviour using adrenalectomised rats. We found that adrenal hormones were necessary for the anxiety-like behaviour to appear. Adrenal removal almost completely suppressed the increase in anxiety-like behaviour caused by vitamin E deficiency despite the low $\alpha$-tocopherol levels. There have been previous reports of an unexplained increase in brain TBARS levels after removal of the adrenal gland ${ }^{(28)}$; however, it was not associated with anxiety-like behaviour. Previous studies have reported a close association between corticosterone and anxiety. Chronic corticosterone administration to mice was reported to induce reduced neurogenesis in the hippocampus and increased anxiety-like behaviour ${ }^{(18)}$. Further, glucocorticoid receptor deletion, corticotropinreleasing factor deletion or corticotropin-releasing factor antagonist administration has been reported to decrease anxietylike behaviour ${ }^{(19-21,29)}$. Additionally, high corticosterone levels under chronic stress were reported to induce morphological spine changes in the prefrontal cortex ${ }^{(22)}$. Moreover, high corticosterone levels under stress have been reported to decrease endogenous cannabinoid, which is an important neuroplasticity regulator and increase anxiety-like behaviour ${ }^{(30,31)}$. These findings demonstrate that chronic exposure to high corticosterone levels affects neural functions and increases anxiety-like behaviour. Previous studies have also reported increased corticosterone levels associated with vitamin E deficiency ${ }^{(32)}$. Although the mechanism underlying increase corticosterone levels remains to be identified, we speculate that the decreased reactivity to corticosterone in the hypothalamus or hippocampus reduces the negative feedback regulation of the hypothalamus-pituitary-adrenal axis and upregulates plasma corticosterone level during stress. Increased corticosterone levels resulting from this mechanism have been observed in depressed patients and could cause emotional disorders ${ }^{(33)}$. Furthermore, vitamin E-deficient rats have been reported to have reduced hippocampal glucocorticoid receptor levels ${ }^{(34)}$.

Many studies have reported a relationship between vitamin $\mathrm{E}$ deficiency and brain functions. Brain monoamine levels, which are important for emotion control, have been reported to be altered by vitamin $\mathrm{E}$ deficiency and this alteration might be related to increased anxiety behaviour during vitamin $\mathrm{E}$ deficiency $^{(12,35)}$. DNA microarray analysis results of $\alpha$-TTP knockout mice brain indicated reduced expression of genes that determine synaptic plasticity and neuronal development ${ }^{(36)}$. Furthermore, oxidative stress has been reported to cause neuroinflammation $^{(37)}$ and neurodegeneration and is thought to cause neurodegenerative diseases such as Alzheimer's disease ${ }^{(38)}$. Further, PLTP knockout mice have been reported to have enhanced memory impairment caused by amyloid $\beta$ and that vitamin $\mathrm{E}$ administration reduces this disorder ${ }^{(39)}$. The increased anxiety-like behaviour observed in present study is considered as one of the early symptoms of emotional disorder occurring from hypothalamus-pituitary-adrenal axis abnormalities that decrease brain function. It has also been reported that oxidative stress may affect human anxiety ${ }^{(40)}$.

Our findings indicate that increased anxiety-like behaviour is an early symptom of vitamin E deficiency that can be recovered by vitamin $\mathrm{E}$ refeeding. Moreover, we confirmed that anxietylike behaviour under social isolation stress can be reduced by taking vitamin $\mathrm{E}$ excess of the required amount. Therefore, taking a higher vitamin $\mathrm{E}$ amount than is currently needed might be effective for maintaining a healthy mental state. Further, we found that adrenal hormones are crucial in the increase of anxiety behaviour due to vitamin E deficiency and that there was a close relationship between the anxiogenic effect of vitamin E deficiency and stress. Present study provides novel findings that demonstrate the necessity and importance of vitamin $\mathrm{E}$ in mental health.

\section{Acknowledgements}

The authors thank the members of the Laboratory of Food Biochemistry at Meiji University for assistance with the animal experiments.

The present study was funded by the Japan Society for the Promotion of Science (JSPS), Grant-in-Aid for Scientific Research (C) 24580202.

The authors' contributions were as follows: A. T. contributed to the study design; Y. T., H. O., Y. O. and K. T. performed the animal experiments, data collection and data analysis; A. T. 
contributed to writing the manuscript. All the authors read and approved the final version of the manuscript.

The authors have no financial or personal conflicts of interest to declare.

\section{References}

1. Traber MG (1996) Vitamin $\mathrm{E}$ in humans: demand and delivery. Annu Rev Nutr 16, 321-47.

2. Di Donato I, Bianchi S \& Federico A (2010) Ataxia with vitamin E deficiency: update of molecular diagnosis. Neurol Sci 31, 511-515.

3. Euch-Fayache GE, Bouhlal Y, Amouri R, et al. (2014) Molecular, clinical and peripheral neuropathy study of Tunisian patients with ataxia with vitamin $\mathrm{E}$ deficiency. Brain 137, 402-410.

4. Traber MG \& Kayden HJ (1989) Preferential incorporation of $\alpha$-tocopherol $v$. $\gamma$-tocopherol in human lipoproteins. Am J Clin Nutr 49, 517-526.

5. Traber MG \& Arai H (1999) Molecular mechanisms of vitamin $E$ transport. Annu Rev Nutr 19, 343-355.

6. Oram JF, Vaughan AM \& Stocker R (2001) ATP-binding cassette transporter A1 mediates cellular secretion of $\alpha$-tocopherol. J Biol Chem 276, 39898-39902.

7. Abe C, Uchida T, Ohta M, et al. (2007) Cytochrome P450dependent metabolism of vitamin $\mathrm{E}$ isoforms is a critical determinant of their tissue concentrations in rats. Lipids $\mathbf{4 2}$, 637-645.

8. Okura Y, Tawara S, Kawai E, et al. (2008) Dietary vitamin E deficiency increases anxiety-related behavior in rats. J Clin Biochem Nutr 43, Suppl. 1, 445-448.

9. Terada Y, Okura Y, Kikusui T, et al. (2011) Dietary vitamin E deficiency increases anxiety-like behavior in juvenile and adult rats. Biosci Biotechnol Biochem 75, 1894-1899.

10. Yokota T, Igarashi K, Uchihara T, et al. (2001) Delayed-onset ataxia in mice lacking $\alpha$-tocopherol transfer protein: model for neuronal degeneration caused by chronic oxidative stress. Proc Natl Acad Sci U S A 98, 15185-15190.

11. Desrumaux C, Risold PY, Schroeder H, et al. (2005) Phospholipid transfer protein (PLTP) deficiency reduces brain vitamin $\mathrm{E}$ content and increases anxiety in mice. FASEB J 19, 296-297.

12. Desrumaux CM, Mansuy M, Lemaire S, et al. (2018) Brain vitamin $\mathrm{E}$ deficiency during development is associated with increased glutamate levels and anxiety in adult mice. Front Behav Neurosci 12, 310.

13. Masood A, Nadeem A, Jamal Mustafa S, et al. (2008) Reversal of oxidative stress-induced anxiety by inhibition of phosphodiesterase-2 in mice. J Pharmacol Exp Ther 326, 369-379.

14. Salim S, Sarraj N, Taneja M, et al. (2010) Moderate treadmill exercise prevents oxidative stress-induced anxiety-like behavior in rats. Behav Brain Res 208, 545-552.

15. Hovatta I, Juhila J \& Donner J (2010) Oxidative stress in anxiety and comorbid disorders. Neurosci Res 68, 261-275.

16. Okura Y, Tawara S, Kikusui T, et al. (2009) Dietary vitamin E deficiency increases anxiety-related behavior in rats under stress of social isolation. BioFactors 35, 273-278.

17. Arborelius L, Owens MJ, Plotsky PM, et al. (1999) The role of corticotropin-releasing factor in depression and anxiety disorders. J Endocrinol 160, 1-12.

18. Murray F, Smith DW \& Hutson PH (2008) Chronic low dose corticosterone exposure decreased hippocampal cell proliferation, volume and induced anxiety and depression like behaviours in mice. Eur J Pharmacol 583, 115-127.
19. Smith GW, Aubry JM, Dellu F, et al. (1998) Corticotropin releasing factor receptor 1-deficient mice display decreased anxiety, impaired stress response, and aberrant neuroendocrine development. Neuron 20, 1093-1102.

20. Tronche F, Kellendonk C, Kretz O, et al. (1999) Disruption of the glucocorticoid receptor gene in the nervous system results in reduced anxiety. Nat Genet 23, 99-103.

21. Heinrichs SC, Pich EM, Miczek KA, et al. (1992) Corticotropinreleasing factor antagonist reduces emotionality in socially defeated rats via direct neurotropic action. Brain Res 581, 190-197.

22. Cook SC \& Wellman CL (2004) Chronic stress alters dendritic morphology in rat medial prefrontal cortex. $J$ Neurobiol 60, 236-248.

23. Oshima Y, Watanabe T, Endo S, et al. (2018) Effects of eicosapentaenoic acid and docosahexaenoic acid on anxiety-like behavior in socially isolated rats. Biosci Biotechnol Biochem 82, 716-723.

24. Leonard SW, Terasawa Y, Farese RV, et al. (2002) Incorporation of deuterated RRR- or all-rac- $\alpha$-tocopherol in plasma and tissues of $\alpha$-tocopherol transfer protein-null mice. Am J Clin Nutr $\mathbf{7 5}$, $555-560$.

25. Cuddihy SL, Ali SS, Musiek ES, et al. (2008) Prolonged $\alpha$-tocopherol deficiency decreases oxidative stress and unmasks $\alpha$-tocopherol-dependent regulation of mitochondrial function in the brain. J Biol Chem 283, 6915-6924.

26. Machlin LJ, Filipski R, Nelson J, et al. (1977) Effects of a prolonged vitamin $\mathrm{E}$ deficiency in the rat. J Nutr $\mathbf{1 0 7}$, 1200-1208.

27. Owen AJ, Batterham MJ, Probst YC, et al. (2005) Low plasma vitamin E levels in major depression: diet or disease?. Eur $J$ Clin Nutr 59, 304-306.

28. Liu J, Yokoi I, Doniger SJ, et al. (1998) Adrenalectomy causes oxidative damage and monoamine increase in the brain of rats and enhances immobilization stress-induced oxidative damage and neurotransmitter changes. Int J Stress Manag 5, 39-56.

29. Timpl P, Spanagel R, Sillaber I, et al. (1998) Impaired stress response and reduced anxiety in mice lacking a functional corticotropin-releasing hormone receptor 1. Nat Genet 19, 162-166.

30. Patel S, Roelke CT, Rademacher DJ, et al. (2004) Endocannabinoid signaling negatively modulates stressinduced activation of the hypothalamic-pituitary-adrenal axis. Endocrinology 145, 5431-5438.

31. Qin Z, Zhou X, Pandey NR, et al. (2015) Chronic stress induces anxiety via an amygdalar intracellular cascade that impairs endocannabinoid signaling. Neuron 85, 1319-1331.

32. South PK, Smith AD, Guidry CA, et al. (2016) Effect of physical restraint on oxidative stress in mice fed a selenium and vitamin $\mathrm{E}$ deficient diet. Biol Trace Elem Res 109, 293-300.

33. Kunugi H, Ida I, Owashi T, et al. (2006) Assessment of the dexamethasone/CRH test as a state-dependent marker for hypothalamic-pituitary-adrenal (HPA) axis abnormalities in major depressive episode: a multicenter study. Neuropsychopharmacology 31, 212-220.

34. Kobayashi N, Machida T, Takahashi T, et al. (2009) Elevation by oxidative stress and aging of hypothalamic-pituitary-adrenal activity in rats and its prevention by vitamin E. $J$ Clin Biochem Nutr 45, 207-213.

35. Adachi K, Izumi M \& Mitsuma T (1999) Effect of vitamin E deficiency on rat brain monoamine metabolism. Neurochem Res 24, 1307-1311.

36. Gohil K, Schock BC, Chakraborty AA, et al. (2003) Gene expression profile of oxidant stress and neurodegeneration 
in transgenic mice deficient in $\alpha$-tocopherol transfer protein. Free Radic Biol Med 35, 1343-1354.

37. Takahashi K, Yanai S, Takisawa S, et al. (2019) Vitamin C and vitamin $\mathrm{E}$ double-deficiency increased neuroinflammation and impaired conditioned fear memory. Arch Biochem Biophys 663, 120-128.

38. Wang X, Wang W, Li L, et al. (2014) Oxidative stress and mitochondrial dysfunction in Alzheimer's disease. Biochim Biophys Acta Mol Basis Dis 1842, 1240-1247.
39. Desrumaux C, Pisoni A, Meunier J, et al. (2013) Increased amyloid- $\beta$ peptide-induced memory deficits in phospholipid transfer protein (PLTP) gene knockout mice. Neuropsychopharmacology 38, 817-825.

40. Islam MR, Ahmed MU, Islam MS, et al. (2014) Comparative analysis of serum malondialdehyde, antioxidant vitamins and immunoglobulin levels in patients suffering from generalized anxiety disorder. Drug Res $\mathbf{6 4}$, 406-411. 